\title{
極薄 Ru キャップ層を用いたスピンバルブ素子の CPP- GMR特性 CPP-GMR in Spin Valve Films with an Ultrathin Ru Cap Layer
}

\author{
阿部慎也* $\cdot$ 山口正彦* ·手束展規,*** 猪俣浩一郎,*** \\ *東北大学大学院工学研究科材料物性学専攻，仙台市青葉区荒巻字青葉 02 (T980-8579) \\ **戦略的創造研究推進事業(CREST)-科学技術振興機構(J ST), 埼玉県川口市本町 4-1-8 (广 332-0012)
}

\begin{abstract}
S.Abe*,M. Yamaguchi* ,N .Tezuka*,** ,K I I nomata*,**
*Department of Material Science, Graduate School of Engineering, Tohoku University, Aobayama 02, Sendai 980-8579,J apan ${ }^{* *}$ Core Research for Evolutional Science and Technology (CREST)-J apan Science and Technology Corporation (J ST), 4-1-8 Honcho, Kawaguchi 332-0012, J apan
\end{abstract}

We have studied the current-perpendicular-to-plane giant magnetoresistance (CPP-GMR) of single spin-valve (SV) films with two different free layers : one is a single ferromagnet layer (conventional), and the other is a ferromagnetic layer with a ruthenium cap layer (Ru cap). When the spacer Cu layer thickness is $2.5 \mathrm{~nm}$ and the Ru layer is $0.45 \mathrm{~nm}$, the Ru cap-type greatly enhances the CPP-GMR, with increasing its value up to $4.3 \%$. We argue that the MR enhancement is probably caused by the spin-dependent scattering due to the strong reflection of majority spins at the $\mathrm{Cog}_{0} \mathrm{Fe} \mathrm{e}_{1} / \mathrm{Ru}$ interface.

Keyword: CPP-GMR, Ru, Enhancement, spin-dependent scattering

\section{1.はじめに}

近 年, Current-Perpendicular-to-Plane Giant Magnetoresistance (CPP-GMR) 素子の研究が盛んに行わ れている.CPP-GMR 素子は, スピン拡散長の推定やスピ ン注入による磁化反転現象 1)を検証するのに適しており， 固体中のスピン制御技術の確立など基礎物理の観点で非 常に重要である. 特にスピン注入による磁化反転の検証に 関しては,近年,急速に研究が進められ， $\mathrm{Co} / \mathrm{Cu} / \mathrm{Co}$ 系の保 磁力差型 CPP-GMR 素子 2)-4)やスピンバルブ型素子 5) にお いて、スピン注入による磁化反転が観測されている.また， 応用上では, 次世代超高密度 HDD における読み出し用へ ッドの技術として注目を集めている.現行の Current-In-Plane (CIP)- GMR ヘッドでは, NOL (Nano Oxide Layer) スペキュラー型を用いても，100 200 Gbit/inch² か限界と予想されているのに対し，スピンバル ブ型 CPP-GMR ヘッドは，200 Gbit/inch 2 を超える技術と して期待されている ${ }^{6)}$. しかしながら , スピンバルブ型の 場合には, MR 比が反強磁性層の抵抗に埋もれてしまい， $\mathrm{CoFeCu}$ 系のシングルスピンバルブ構造においても MR 比 が約 $0.7 \%$ と低いことが問題視されている

我々は，Co中にRu不純物が介在した場合には $\alpha=\rho_{\downarrow} / \rho_{\text {小 }}$ $=0.22^{7}$ であることに着目し, $\mathrm{C} 09_{0} \mathrm{Fe} \mathrm{e}_{10} / \mathrm{Ru} / \mathrm{CO}_{90} \mathrm{Fe} \mathrm{e}_{10}$ 反平行 結合 $(S y A F)$ 素子をフリー層に用いたスピンバルブ型 CPP-GMR 素子を作製した結果，CPP-GMR が大きくエン ハンスすることを見出した ${ }^{8)}$. この原因は $\mathrm{C} O{ }_{0} 0 \mathrm{Fe} \mathrm{e}_{10} / \mathrm{Ru}$ 界 面で多数(majority)スピンが強く散乱(反射)されるためと 推定した . 本研究はこれを確認するため, 極薄 Ru キャッ プを有するスピンバルブ型 CPP- GMR 素子を作製し，光の CPP-GMR 特性を明らかにすることを目的とする .

\section{2 . 実験方法}

超高真空ヘリコンスパッタ装置を用いて, 熱酸化膜付き
Si 基板上に, $\mathrm{Ta}(2.5 \mathrm{~nm}) / \mathrm{Cu}(5 \sim 20 \mathrm{~nm}) / / \mathrm{rMn}(10 \mathrm{~nm})$ /CogoF e 10 (tp nm)/Cu(dcu nm)/free layer/Cu(5 nm)/Ta(3 $\mathrm{nm})$ の膜構成で成膜を行った free layer には，(1) $\mathrm{Cog}_{0} \mathrm{Fe}_{10}\left(t_{f} \mathrm{~nm}\right)$ : conventional タイプ , (2) $\mathrm{Cog}_{0} \mathrm{~F} \mathrm{e}_{10}\left(t_{\mathrm{f}}\right.$ $\mathrm{nm}) / \mathrm{Ru}($ oku nm) : Ru cap タイプの 2 種類を用いた . 膜厚 は光れ帒れ $t_{\mathrm{p}}=3 \sim 9 \mathrm{~nm}, d c_{u}=2.5 \sim 6 \mathrm{~nm}, t_{\mathrm{f}}=2 \sim 17 \mathrm{~nm}$ ， $d_{k u}=0.1 \sim 0.7 \mathrm{~nm}$ である 到達真空度 $1.0 \times 10^{-6} \mathrm{~Pa}$ 以下， $\mathrm{Ar}$ ガス圧 $4.0 \times 10^{-2} \sim 9.0 \times 10^{-2} \mathrm{~Pa}$, 投入電力 $2.5 \sim 7.5$ $\mathrm{W} / \mathrm{cm}^{2}$ とし, 約 200 Oe の磁場を印加しながら室温基板温 度で成膜した . 成膜後, 電子線リソグラフィーと Ar イオ ンミリング装置を用いて,まず下部電極をパターニングし， 続いて素子部の周りをミリング, 弚の後, 絶縁層として $\mathrm{SiO}_{2}$ をスパッタした・最後に,上部電極として $\mathrm{Cu}(70 \mathrm{~nm})$ を成膜し, 微小CPP-GMR 素子を作製した . 素子は 1 ウエ ハー上に 12 個作製し,素子サイズは断面積 $A=0.08 \sim 4 \mu$ $\mathrm{m}^{2}$ の範囲で变化させた . Fig.1 に試料の模式图を示す . 抵 抗は直流4端子法を用い \pm 1000 Oe 下で室温で測定した。 また，MR 比は試料の抵抗 $R$ および抵抗変化 $\Delta R$ のサイズ 依存性から $R A$ および $\Delta R A$ を算出し, $\mathrm{MR}$ 比は $\mathrm{MR}=\Delta$ $R A / R A \times 100(\%)$ 用いて評価した 。 (a)

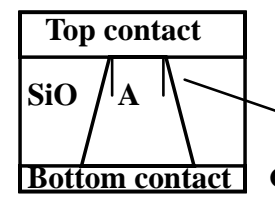

(b)

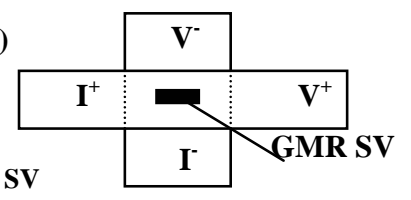

Fig. 1 The (a) cross section and (b) top view of the fabricated CPP-GMR element. The element's size is defined as $A$.

\section{3 . 実験結果および考察}

\subsection{Conventi onal タイプにおける GMR特性}

Fig.2に, tree $=5 \mathrm{~nm}$ に対する conventional タイプの CPP-GMR 素子における $R, \Delta R, \mathrm{MR}$ のサイズ依存性を 示す.ピンド層厚およびスペーサーCu 層厚は光れ光れ $t_{\mathrm{p}}=$ $3(\mathrm{~nm}), d \mathrm{C}_{\mathrm{u}}=6(\mathrm{~nm})$ と一定である.$R$ および $\Delta R$ のサイズ 依存性は, 対数プロットで傾き-1の直線関係を示している ことがわかる.これから本素子は正常に作製されていると 言える。スピン拡散長が十分に長いと仮定した場合， Valet-Fert (V-F) モデルにより $\Delta R A$ は次式で表される ${ }^{9}$.

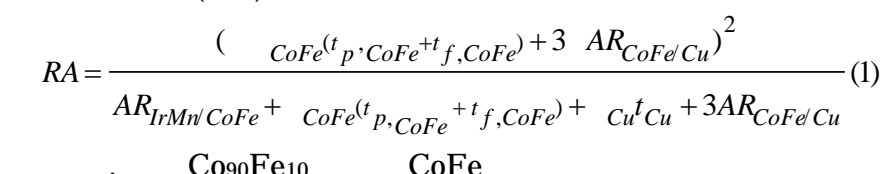




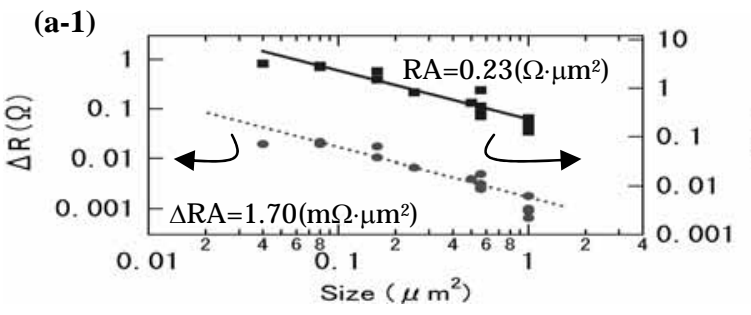

(a-2)

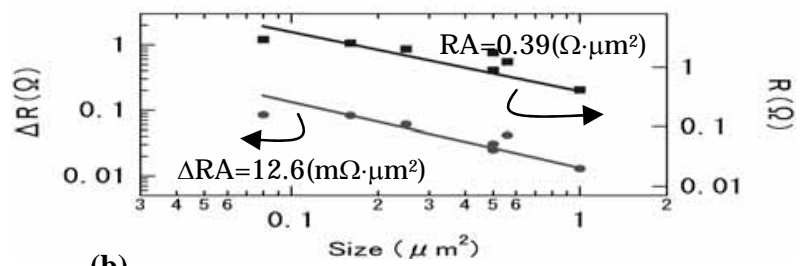

(b)

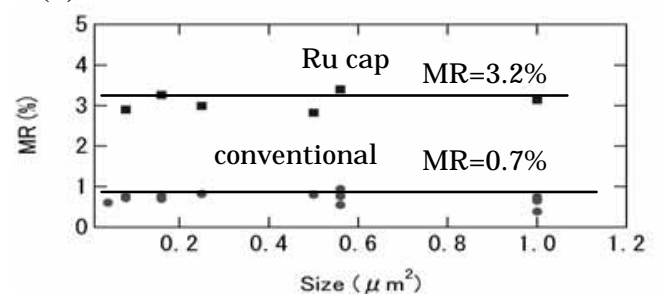

Fig. 2, $\Delta R$ and $R$ for conventional type (a-1) and Ru cap type (a-2) CPP-GMRs and MR ratio (b) as a function of the pillar size. Dotted line denotes the results for $\Delta R A$ calculated by using the $\mathrm{V}-\mathrm{F}$ model.

パラメータ $(\beta \mathrm{CoFe}=0.65)^{9)}, \gamma$ は CoF e/Cu 界面における 非対称パラメータ $\left(\gamma \mathrm{CoFe} / \mathrm{Cu}=0.75{ }^{9}\right)$ である.また，

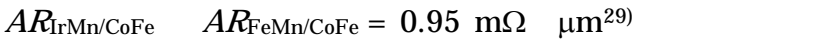

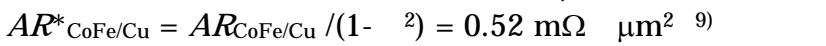
抵抗 $, \rho^{*}=\rho /\left(1-\beta^{2}\right), \rho$ CoF $=15.4 \mu \Omega-\mathrm{Cm}$ および $\rho \mathrm{Cu}=$ $4.5 \mu \Omega-\mathrm{cm}$ は光れ光れ CoFeおよびCu の比抵抗を示す. (1)式より, $\Delta R A=1.70 \mathrm{~m} \Omega \cdot \mu \mathrm{m}^{2}$ と計算される .Fig.2 (a-1) 中の破線は，V-F モデルから得られた計算值であり，実験 值と計算値がほぼ一致していることがわかる．また， $R A$ は $0.23 \Omega \cdot \mu \mathrm{m}^{2}$ が得られた .さらに，MR 比はサイズに依 存せず $M R=0.7 \%$ 程度で一定值を示している .これらは， 一般に報告されているスピンバルブ型 CPP-GMR 素子と同 樣の結果 6)である .

\section{2 Ru cap タイプにおける CPP-GMR 特性}

Figs.2 (a-2)および(b)に ,Ru cap タイプの CPP-GMR 素 子における， $R, \Delta R$ および MR 比の素子サイズ依存性を 示す. $t_{\text {free }}=5 \mathrm{~nm}$ とし，ピンド層厚、スペーサーCu 厚およ びRu 厚はそれ光れ $t_{p}=3 \mathrm{~nm}, d c u=2.5 \mathrm{~nm}, d k u=0.2 \mathrm{~nm}$ とした. $\Delta R$ の素子サイズ依存性には conventional タイプ と同樣の傾向が見られ, 傾き-1 の直線から $\Delta R A$ を算出す ると , $\Delta R A=12.6 \mathrm{~m} \Omega \cdot \mu \mathrm{m}^{2}$ であり, conventional タイ プに比べ一桁大きな值を示した．また，同樣にして $R$ の素 子サイズ依存性から， $R A=0.39 \Omega \cdot \mu \mathrm{m}^{2}$ が得られた .さ らに, MR 比は素子サイズによらず 3.2\%程度であることが わかる . 以上より, Ru cap タイプにおいて conventional タイプに比べ約 5 倍の MR 比のエンハンスが観測された .

次にこの MR 比エンハンスのメカニズムを明らかにする
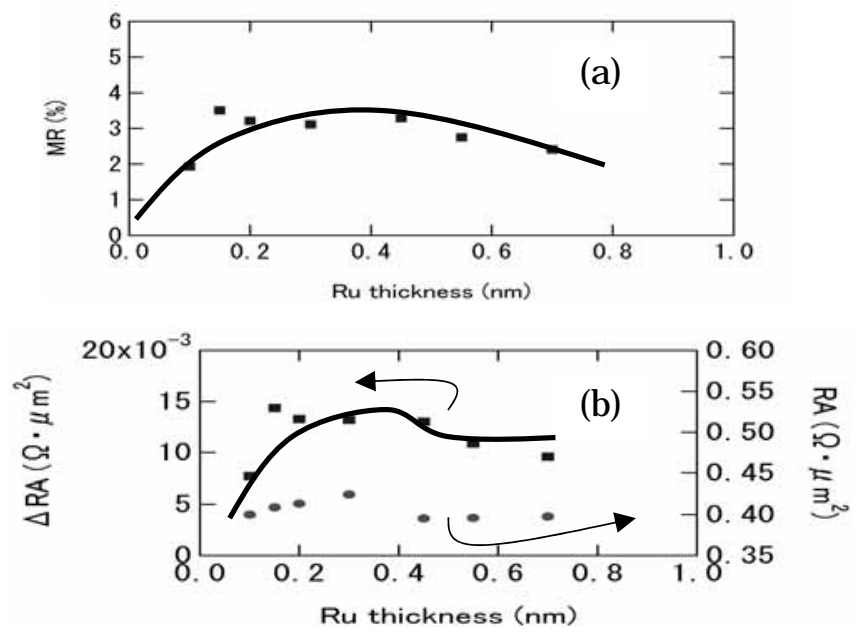

Fig. 3 (a) MR ratio and (b) $\Delta R A(\square), R A(\mathbf{O})$ as functions of the Ru thickness ( $\left.d_{k u}\right)$ for $R u$ cap-type CPP-GMRs.

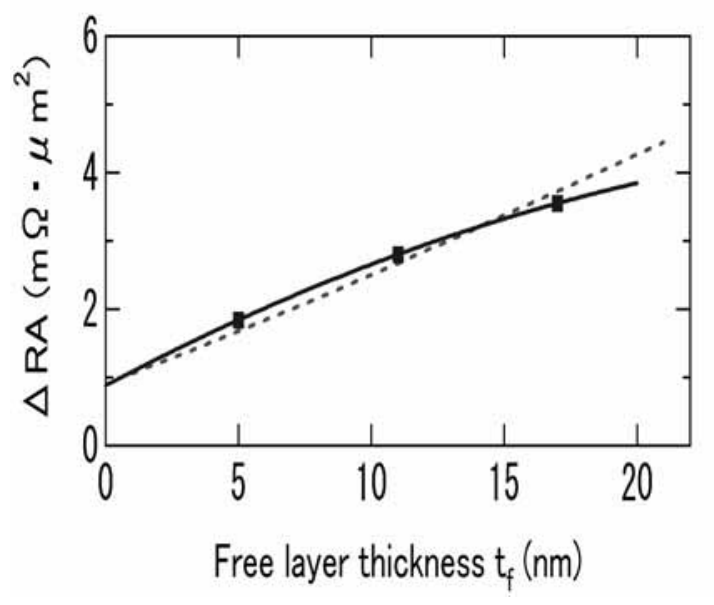

Fig.4 $\triangle R A$ as a function of the free layer thickness for conventional-type CPP-GMRs. Dot lines denote the results for $\triangle R A$ calculated by using the $\mathrm{V}-\mathrm{F}$ model.

ため,MR 比の磁性層および非磁性層厚 $\left(t_{\mathrm{p}}, t_{\mathrm{f}}, d \mathrm{cu}_{\mathrm{u}}, d_{\mathrm{k} u}\right)$ 依存性を調べた .

\section{3 Ru cap タイプにおける MR比の磁性および非磁性厚依 存性}

3. 3. 1 MR比の Ru 厚依存性

Fig.3にRu cap タイプにおける MR 比および $\Delta R A$ の $\mathrm{Ru}$ 厚依存性を示す . Ru 厚は 0.1 0.7 nm の範囲で変化さ せ , 他の磁性層および非磁性層膜厚は, $t_{\mathrm{p}}=3(\mathrm{~nm}), d c_{\mathrm{u}}=$ $2.5 \mathrm{~nm}, t_{\mathrm{f}}=5 \mathrm{~nm}$ で一定とした. MR 比は, $\mathrm{Ru}$ 厚が 0.2 $0.45 \mathrm{~nm}$ と極薄い範囲で最大值を示し，0.45 nm 以上では $\mathrm{Ru}$ 厚の増加に伴い減少することがわかる . Ru cap に伴う $\Delta R A$ のエンハンスは CoF e/Ru 界面で生じることを考慮す ると, この MR 比の減少は, スピン依存散乱に寄与しない $\mathrm{Ru}$ 厚の増加による $\Delta R A$ の減少に起因し , $0.15 \mathrm{~nm}$ 以下で の $\mathrm{MR}$ の減少は Ru の不連続膜による $\Delta R A$ の減少が原因 であると考えられる . 

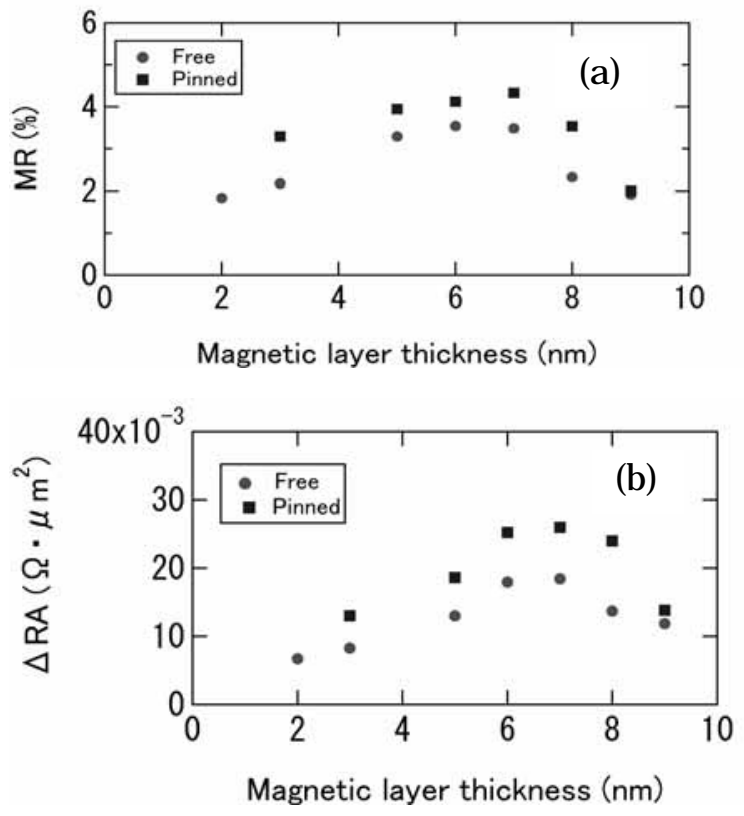

Fig. 5 (a) MR ratio and (b) $\triangle R A$ as functions of the free and pinned layer thicknesses for $\mathrm{Ru}$ cap type CPP-GMRs.

\section{3. 2 MR比の磁性層厚依存性}

まず初めに, conventional タイプにおいて CoFe のスピ ン拡散長を推定した . Fig.4 に conventional タイプにおけ る $\Delta R A$ のフリー層厚依存性を示す.破線が CoFeのスピン 拡散長を無限大と仮定して得られる V-F モデルによる計算 值，各点 $(\boldsymbol{\square})$ が実験值を示している．実線は見やすくす るため実験值を滑らかに繋いだ線である.Fig.4より，フリ 一層厚が $15 \mathrm{~nm}$ 以上でも $\Delta R A$ が増加傾向を示し, また 10 12 nm において実験值が V-F モデルからはずれている ことがわかる.以上より, CoFeのスピン拡散長は 10 12 $\mathrm{nm}$ と推定できる．この結果は他の報告 9)とほぼ一致して いる.Fig.5に MR 比 , $\Delta R A$ のフリ一層厚およびピンド層 依存性を示す．フリー層厚依存性に関しては $t_{\mathrm{p}}=3 \mathrm{~nm}$ で 固定して $t_{f}$ を 2 - $9 \mathrm{~nm}$ まで変化させ, ピンド層厚依存性に ついては $t_{f}=5 \mathrm{~nm}$ で固定し， $t_{\mathrm{p}}=3 \sim 9 \mathrm{~nm}$ とした .また他 の非磁性層厚は, $d_{c u}=2.5 \mathrm{~nm}, d_{k u}=0.45 \mathrm{~nm}$ で一定とし た . Fig.5より, MR 比と $\Delta R A$ のフリー層厚およびピンド 層厚依存性は同樣の傾向を示し, 磁性層が厚くなるにつれ て MR と $\Delta R A$ ははじめ増加し，6 7 $\mathrm{nm}$ で最大值をとり， それ以上では減少している．はじめの増大はスピン依存バ ルク散乱の寄与であり, 兴の後の減少は磁性層中でのスピ ン緩和が原因であると考えられる．また，ピンド層厚の増 加に伴う MR 比の減少には, ピンド層の一方向異方性磁界 の減少も影響していると考えられる．

以上より Ru cap タイプは conventional タイプの傾向と は異なり，M R 比および $\Delta R A$ の最大值が 6 7 $(\mathrm{nm})$ で得ら れていることから，CoFe/Ru 界面における majority スピ ンの散乱(反射)による，スペーサーとフリー層間でのスピ ン依存多重散乱が示唆される。これを調べるため, 現象論 的な次式 10)を用いて計算を行った .

$\Delta R / R=(\Delta R / R)_{\max }\left[1-\exp \left(-t_{F} / l_{s f}\right)\right] /\left(1+t_{F} / t_{\text {rest }}\right)$ (2)

ここで， t F はフリーまたはピンド層厚，/sf はスピン拡散長

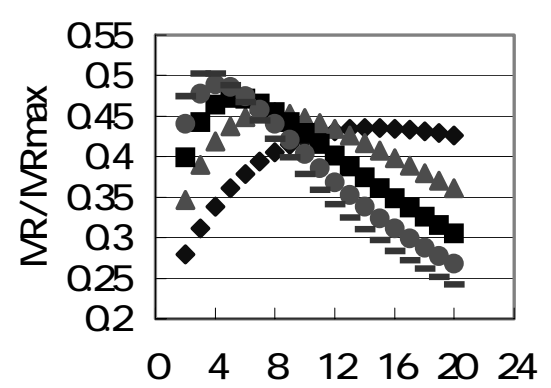

(a)

Free layer thickness $(\mathrm{nm})$

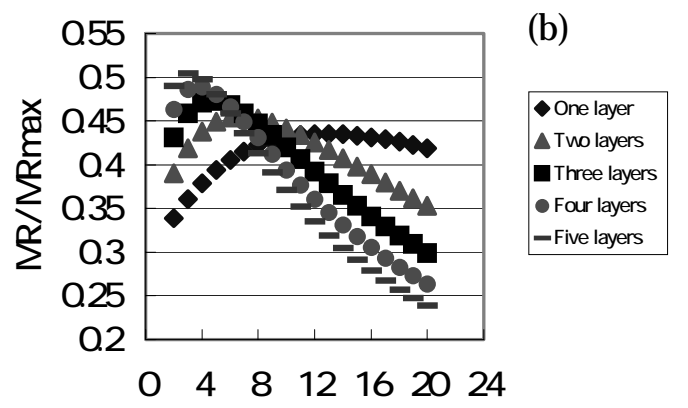

Pinned layer thickness (nm)

Fig. 6 Calculation of the relative CPP-GMR as a function of the thickness of the (a) free and (b) pinned layers for Ru cap-type CPP-GMR.

$($ CoFe : $12 \mathrm{~nm})$, trest は t F 以外の抵抗に関与する膜厚であ る.Fig.6に(2)式から得られた MR 比のフリ一層厚(a)お よびピンド層厚(b)依存性を示す.計算は, CoF e/Ru 界面に おけるスピン依存散乱(反射)を仮定し，majority スピンが フリー層を 1 回伝導した場合を 1 層 $\left(t_{\mathrm{F}}\right), \mathrm{CoF} e / \mathrm{Ru}$ 界面で 散乱(反射)され再びフリー層中に戻る場合を 2 層 $(2 t \mathrm{~F})$, 光 のスピンがピンド層/スペーサー界面でスピン依存散乱を 受け，もう一度フリ一層を伝導する場合を 3 層 $(3 t F)$ と仮 定して計算を行った．Fig.6より，MR 比および $\Delta$ RA が最 大値を示すフリー層厚およびピンド層厚 6 7 nm に着目す ると，どちらの場合も 2 層を仮定して計算を行った結果が 実験とほぼ一致している .これから，CoFe/Ru 界面におけ る majority スピンの散乱(反射)が MR エンハンスの原因で あると考えられる

従来, フリー層との静磁結合を低減させるため, 反強磁 性層の上にピンド層として CoF e/Ru/CoFe 反平行結合膜を 設けているが , この場合には CPP-GMR のエンハンスはな (11)。これは反平行結合した CoFe/Ru/CoFe ピンド層内 の複杂倠なスピン依存散乱によって実効的なスピン分極率が 低下し,$\Delta R$ が小さくなるためと考えられている ${ }^{11)}$. 尚， 本研究で示したRu capによるCPP-GMRのエンハンスは, 最近我々が見出した Ru cap によるスピン注入磁化反転の 電流密度低減効果 5)とコンシステントである。

\subsubsection{MR比のスペーサー (Cu) 膜厚依存性}

3-3-2 と同樣に , まず初めに conventional タイプにおい て Cu のスピン拡散長を推定した . Fig.7 に $\Delta R A$ のスペー サーCu 厚依存性の実験および現象論的な(3)式 10)によるフ イッティングを示す。 


$$
\Delta R A=(\Delta R A)_{\max } \exp \left(-t_{N M} / l_{s f}\right)
$$

ここで， $t_{\mathrm{NM}}$ は Cu 膜厚，/sf は Cu のスピン拡散長である . Fig.7より，(3)式を用いたフィッティングから Cu のスピ ン拡散長は $25 \mathrm{~nm}$ と求められる.スピン拡散長は, 自由電 子モデルを仮定すると(4)式 12)で示される .

$$
I_{s f}=C \sqrt{\lambda_{s f} / \rho_{C u}} \quad C=\sqrt{m v_{F} / 6 n e^{2}}
$$

ここで $, C=1.048 \times 10^{-8}\left(\Omega^{1 / 2} \mathrm{~m}\right), \lambda_{s f}$ はスピンフリップ長 (Cu の場合, 室温で $\left.350 \mathrm{~nm}^{11)}\right), m$ は電子の質量,$n$ は電 荷密度, Vkはフェルミ速度, $e$ は電荷を示す. (4)式と実験 值である $\rho \mathrm{cu}=4.5 \mu \Omega \cdot \mathrm{cm}$ より $/ \mathrm{sf}=29 \mathrm{~nm}$ が得られる. この計算は実験結果とほぼ一致している .

Fig.8に，MR 比のスペーサー (Cu) 膜厚依存性を示す. $\mathrm{Cu}$ 層厚 $\left(d_{\mathrm{c}}\right)$ を $2.5 \sim 6 \mathrm{~nm}$, フリー層厚 $\left(t_{\mathrm{f}}\right)$ を $2 \sim 3 \mathrm{~nm}$ まで変化させ, 他の磁性層, 非磁性層膜厚は, $t_{\mathrm{p}}=3(\mathrm{~nm})$, dku $=0.45 \mathrm{~nm}$ で一定とした．Fig.8より，MR 比は Cu 膜 厚が増加するにつれて減少し, フリ一層膜厚が厚い程，Cu 膜厚に対する MR 比の減少が大きいことがわかる これは， $\mathrm{CoFe} / \mathrm{Ru}$ 界面における majority スピンの散乱(反射)により $\mathrm{Cu} / \mathrm{CoFe}$ (free)でスピン依存多重散乱が生じ，Cu 層厚が厚 くなるにつれて Cu 中でのスピン緩和が増加すること，およ びフリー層厚がスピン拡散長に近づく程 Cu 層中でスピン

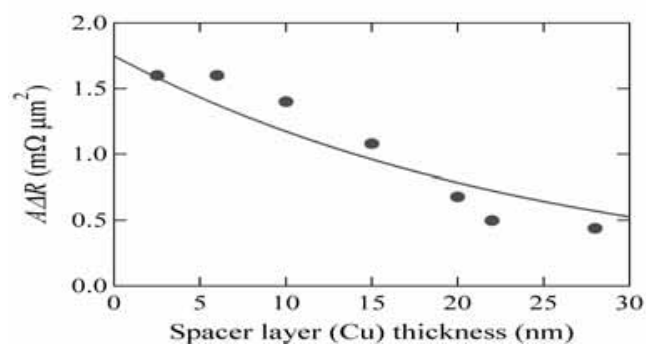

Fig. $7 \Delta R A$ as a function of the spacer (Cu) layer thickness and calculation of the relative $\triangle R A$ as functions of the thickness of the spacer $(\mathrm{Cu})$ layer for conventional-type CPP-GMRs .

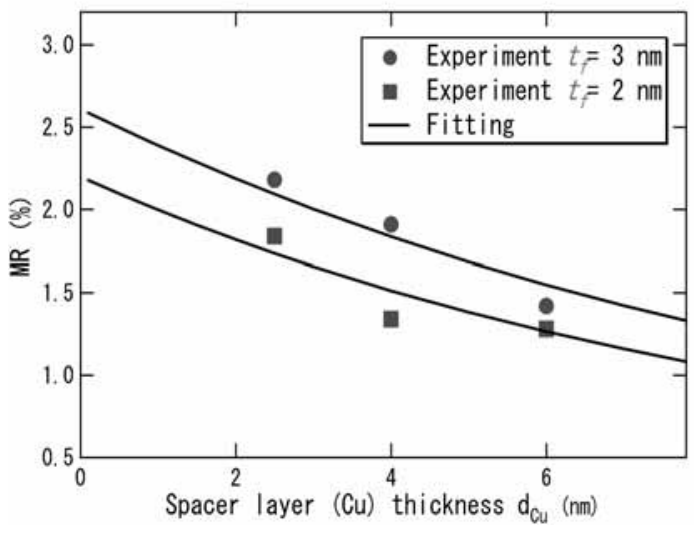

Fig. $8 \mathrm{MR}$ ratio as a function of the spacer $(\mathrm{Cu})$ layer thickness and calculation of the relative CPP-GMR as functions of the thickness of the spacer (Cu) layer for $\mathrm{Ru}$ cap-type CPP-GMRs with a free layer thicknesses of 2 $\mathrm{nm}(\mathbf{\square})$, and $3 \mathrm{~nm}(\mathbf{O})$.
緩和し易いことが原因であると考えられる．このMR 比の $\mathrm{Cu}$ 膜厚依存性について，Cu スペーサ中でのスピン緩和と 同時に, 磁性層中でのスピン緩和を考慮した現象論的な(5) 式 10)を用いて計算を行った .このとき磁性層厚依存性と同 樣の考えで 2 層 $(2 t$ F $)$ を仮定した .

$\Delta R / R=(\Delta R / R)_{\max } \frac{\exp \left(-t_{N M} / l_{s f_{C u}}\right) \exp \left(1-t_{F} / l_{s f_{C o F e}}\right)}{\left(1+t_{N M} / t_{\text {rest } 1}\right)\left(1+t_{F} / t_{\text {rest } 2}\right)}$

ここで , $t_{\mathrm{NM}}$ は $\mathrm{Cu}$ 膜厚で, 弚のスピン拡散長は $/ \mathrm{sf}(\mathrm{Cu})=25$ $\mathrm{nm}, \mathrm{CoFe}$ のスピン拡散長は $/ \mathrm{sf}(\mathrm{CoF})=12 \mathrm{~nm}$ を用いた . Fig.8に，( $\Delta R / R)_{\max }$ を変数とし，上記計算から得られた $\mathrm{MR}$ 比の $\mathrm{Cu}$ 膜厚依存性を示す. MR 比は, $\mathrm{Cu}$ 膜厚が 2.5 $6(\mathrm{~nm})$ の範囲で減少するという実験を再現しており，また， $\mathrm{Cu}$ 膜厚の増加に対する MR 比の減少は,CoFeの膜厚 $3 \mathrm{~nm}$ の方が $2 \mathrm{~nm}$ より大きいことがわかる.以上より ,CoFe/Ru 界面における majority スピンの散乱(反射)とスピン拡散長 を考慮することで，MR 比のスペーサー厚依存性か説明で きる .

\section{4 .まとめ}

極薄 Ru cap を用いたスピンバルブ型 CPP (Current Perpendicular to Plane) -GMR 素子を作製した結果，光の GMR 特性について以下の知見を得た 。

(1)CPP-GMR は最大で約 4.3\% が得られ, Conventional タイプと比較して約 5 倍のエンハンスを示した .

(2)CPP-GMR の最大值は, Ru 厚が $0.2 \sim 0.45 \mathrm{~nm}$ と極薄い 膜厚において得られた .

(3)スペーサー $(\mathrm{Cu})$ 厚 $(2.5 \sim 6 \mathrm{~nm})$ の増加に伴い $\mathrm{MR}$ 比 は減少し, フリー層厚か増加するとともに光の減少率は増 加した .

これらの結果は， $\mathrm{CO}_{90} \mathrm{Fe}_{10} / \mathrm{Ru}$ 界面による majority スピ ンの散乱(反射)を考慮することで説明できる．

謝辞 本研究は科研費補助金特定領域研究 B (14076202), 基盤研究 A (15206074), 平成 15 年度産業技術研究助成 および文部科学省のIT プログラム RR2002 の研究助成に より行われた .

\section{Ref er ences}

1) J.C. Slonczewski, J. Magn. Magn. Mater. 159, L1 (1996).

2) J.A.Katine, F.J.Albert, R.A.Buhrman, E.B.Myers, and D .C.Ralph, Phys. Rev. Lett. 84, 3149 (2000).

3) F.J.Albert, J.A.Katine, R.A.Buhrman, and D.C.Ralph, Appl. Phys. Lett. 77, 3809 (2000).

4) J.Grollier, V. Cros, A.Hamzic, J. M. George, H. Jaffres, A.Fert, G.Faini, J.Ben Youssef and H.Legall, Appl. Phys.Lett. 78, 3663 (2001).

5) Y. Jiang, S. Abe, T. Ochiai, T. Nozaki, A. Hirohata, N. Nezuka and K. Inomata, Phys. Rev. Lett., 92, 167204 (2004).

6) H.Yuasa, H.Fukuzawa, H.Iwasaki, M.Yoshikawa, K.Koi, M.Takagishi and M.Sahashi : J. Magn. Soc. Jpn. 26, 942 (2002).

7) I.A.Campbell and A.Fert : Ferromagnetic Materials Vol.3, North-Holland Publishing Co., 1982.

8) Y.Jiang, S.Abe, .Nozaki, N.Tezuka, and K.Inomata, Appl. Phys. Lett., 83, 2874 (2003), Phys. Rev. B 68, 224426 (2003).

9) A.C.Reilly, W.Park, R.Slater, B.Ouaglal, R.Loloee, W. P. Pratt Jr., and J. Bass : J. Magn. Magn. Mater. 195, L269 (1999).

10) N.Stelkov, A.Vedyaev and B. Dieny : J. Appl. Phys. 94, 3278 (2003).

11) N. C. Emley, F. J. Albert, E. M. Ryan, I. N. Krivorotov, D. C. Ralph and R. A. Buhman, Cond-mat/0401483, 24 Jan. (2004).

12) B.Voegeli, A.Blondel, B. Doudin, J.-Ph. Ansermet : J. Magn. Magn. Mater. 151, 388 (1995).

2004 年 4 月 2 日受理，2004 年 7 月 20 日採録 